\title{
Ensino de História e Currículo: interfaces teóricas e metodológicas
}

History Teaching and Curriculum: theoretical and methodological interfaces

Isabelle de Lacerda Nascentes*

Sérgio Armando Diniz Guerra Filho**

\section{Monteiro, Ana Maria (et al.) \\ Pesquisa em Ensino de História: entre desafios epistemológicos e apostas políticas}

Rio de Janeiro: Mauad X; Faperj, 2014. 280p.

Abordando diferentes perspectivas teórico-metodológicas e múltiplas abordagens epistemológicas, o livro ora resenhado é uma coletânea composta por 16 artigos, contando com uma apresentação elaborada pelas organizadoras - Ana Maria Monteiro, Carmen Teresa Gabriel, Cinthia Monteiro de Araújo e Warley da Costa - e um prefácio de Circe Fernandes Bittencourt. Ao longo do trabalho, predomina a marca institucional do lugar de pertencimento dos autores envolvidos, pois estes integram o Núcleo de Estudos de Currículo da Universidade Federal do Rio de Janeiro (NEC/UFRJ), sendo em sua maioria também vinculados ao Laboratório de Estudos e Pesquisas em Ensino de História (LEPEH/UFRJ). Essa especificidade confere coerência interna, apesar da heterogeneidade nos pontos de vista, em torno de uma questão-chave: o reconhecimento desse campo de pesquisa como fronteira permeável em que referenciais de ambas as áreas - Educação e História - encontram-se articulados.

Há grande diversidade temática entre os artigos, alguns dos quais são extratos de pesquisas de mestrado e doutorado no âmbito NEC/LEPEH. Entre os vinte autores e autoras da coletânea há, também, grande diversidade no que

\footnotetext{
* Professora de História da rede pública do estado do Rio de Janeiro (Seduc/RJ); aluna do Mestrado Profissional em Ensino de História da Universidade Federal Rural do Rio de Janeiro (ProfHistória/ UFRRJ). Seropédica, RJ, Brasil. isanascentes@hotmail.com.br

** Doutor em História Social. Centro de Artes, Humanidades e Letras (CAHL), Universidade Federal do Recôncavo da Bahia (UFRB). Cachoeira, BA, Brasil. sadgfilho@gmail.com
} 
tange à filiação institucional: são docentes do Ensino Superior, docentes da Educação Básica, pesquisadores; doutores, mestres, graduados, mestrandos e doutorandos.

O conjunto de textos reunidos no livro oferece subsídios consistentes para a discussão dos impasses epistemológicos contemporâneos e apostas políticas no cenário da educação básica pública, particularmente no campo de ensino da referida disciplina, compreendido como um espaço de disputas e variadas possibilidades investigativas.

A proposta explicitada pela obra contribui substancialmente para o adensamento do debate acadêmico atual, propondo novas perspectivas com base no olhar de pesquisadoras e pesquisadores em relação ao "espaço-tempo de fronteira” entre Educação e História, ambiente no qual se reconfiguram distintas interpretações a partir das interações dialéticas entre os dois campos de saber. Dessa forma, a publicação reúne análises diversificadas sobre currículo, teoria, ensino, historiografia, livro didático, tensionamentos políticos e identitários, legislação educacional, experiências e saberes docentes e demandas sociais, entre outros aspectos inter-relacionados ao "fazer pesquisa" em História escolar.

O propósito central das discussões converge para o enfrentamento dos dilemas político-institucionais ligados ao reconhecimento e valorização do potencial da escola pública como lócus privilegiado de difusão e democratização de bens culturais, incluindo o conhecimento científico. E paralelamente, está vinculado a uma intencionalidade, a um posicionamento político em defesa da função social do conhecimento histórico como instrumento cognitivo relevante para a significação de nossas experiências temporais diante das exigências do momento presente. Ao mesmo tempo, assume um desafio epistemológico, articulando campos distintos e mobilizando discursos da historiografia, das teorias do currículo, da didática e da pedagogia que construam sentido e legitimidade para o ensino da disciplina de História.

Os textos foram organizados em três blocos temáticos intitulados, respectivamente, "diálogos teóricos possíveis"; "aula de História como espaço-tempo de fronteira" e "livros didáticos de História e pesquisa em ensino de História - múltiplas apropriações”.

A primeira parte compõe-se de cinco artigos que discutem a relação entre História e Educação, enfatizando seus aspectos teórico-metodológicos com 
centralidade no debate epistemológico. O texto de abertura, "Currículo de História e narrativa: entre desafios epistemológicos e apostas políticas", das organizadoras Ana Maria Monteiro e Carmen Teresa Gabriel, convida à reflexão sobre os sentidos de narrativa, suas possibilidades e limites epistemológicos para problematização de questões educacionais contemporâneas, dialogando com referenciais pós-críticos, com destaque para Stuart Hall, bem como fundamentando-se no paradigma narrativista (Hartog e Ricoeur). Em seguida, Fernando de Araújo Penna nos apresenta "A Relevância da Didática para uma Epistemologia da História”. O autor propõe uma discussão teórica sobre a epistemologia da disciplina, para além do campo de produção acadêmica, destacando a relação desses saberes com um espectro social mais amplo. Partindo de um viés historiográfico, Penna sugere uma nova apropriação do conceito de operação historiográfica tecido por Certeau, articulando-o ao conceito de transposição didática proposto por Chevallard para estabelecer uma conexão entre Epistemologia e Didática, em um movimento de deslocamento da produção de conhecimento histórico escolar para o âmbito da operação historiográfica, tornando Didática e Epistemologia “indissociáveis” (p.50).

Os três artigos subsequentes introduzem outras perspectivas de articulação entre História e Educação, possibilitadas pela análise do currículo e da trajetória dessa disciplina no contexto escolar brasileiro. Em seu trabalho intitulado: "A História e os Estudos Sociais, entre tradição acadêmica e tradição pedagógica: o Colégio Pedro II e a reforma educacional da década de 1970”, Beatriz Boclin Marques dos Santos estuda o impacto e as resistências da Lei de Diretrizes e Bases 5.692/1971 no currículo daquela instituição, onde, a despeito da orientação legal, a disciplina História manteve-se como disciplina autônoma. Investiga as características da dinâmica curricular da disciplina Estudos Sociais imposta em 1971 e suas implicações para o ensino de História, referenciando-se nos "padrões de estabilidade e mudança" propostos por Ivor F. Goodson. O trabalho de Rodrigo Lamosa, "O ensino de História e as transições paradigmáticas no contexto da nova regulação do trabalho docente" traz importantes considerações sobre as transformações no ensino de História e nas condições e formas de regulação das atividades profissionais docentes nessa área, a partir do período de redemocratização. Lamosa demonstra que as avaliações externas e as parcerias empresariais têm empurrado o ensino de História a uma pedagogia tradicional, posto que "os modelos baseados no 
adestramento dos alunos para a realização dos exames estão sendo difundidos pelas escolas" (p.77).

Posteriormente, Marcele Xavier Torres e Marcia Serra Ferreira, no artigo "Currículo de História: reflexões sobre a problemática da mudança a partir da Lei 10.639/2003”, tecem, em diálogo com Hannah Arendt, considerações a respeito da inserção do componente História e cultura africana e afro-brasileira, avaliando seus impactos para o ensino de História. As autoras reconhecem a importância de instrumentos legais, mas afirmam a sua insuficiência na mudança de uma tradição eurocêntrica se a tradição expressa na cultura escolar não for, ela própria, objeto de mudanças.

Nos cinco textos reunidos no segundo bloco da coletânea, o foco principal está na análise das relações discursivas estabelecidas entre sujeitos do processo ensino-aprendizagem e conhecimento histórico escolar. Abrindo essas discussões encontra-se o artigo "Identidades Sociais: produção de sentido nas enunciações de uma docência”, no qual Ana Paula Taveira Soares apresenta resultados de sua pesquisa empreendida no mestrado sobre currículo e linguagem nas negociações de sentidos que constituem, qualificam e transformam as marcas identitárias presentes nos discursos dos docentes em suas aulas de História, enquanto práticas discursivas sociais. No artigo seguinte, "A produção de sentido na História ensinada e sua relação constitutiva com o espaço-tempo", Patrícia Bastos de Azevedo reflete sobre a História ensinada, as contingências e os constrangimentos que permeiam esse tempo-espaço composto por múltiplas forças histórico-sociais que compõem a cultura escolar e limitam/delimitam a ação do professor, compreendido como protagonista desse processo, assim como o aluno é o agente central da História aprendida. Partindo das potencialidades dialógicas entre ensino de História, a teoria do discurso de Laclau e Mouffe e os aportes da transposição didática de Chevallard, Warley da Costa, no texto "Currículo de História e produção da diferença: fluxos de sentido de negro recontextualizados na História ensinada”, analisa as configurações das narrativas históricas produzidas pelos discentes na realização de uma atividade proposta em sala de aula para alertar sobre a necessidade de deslocar "leituras dicotômicas e conservadoras de mundo" (p.144), que reatualizam discursos racistas, a despeito do alargamento da presença de conteúdos não binários sobre o tema. Costa evidencia esse espaço como território curricular de lutas político-identitárias que envolvem as relações 
étnico-raciais contemporâneas. Márcia Cristina de Souza Pugas apresenta o texto "Currículo, Diferença, Identidade e Conhecimento Histórico Escolar", o qual compreende parte da pesquisa de mestrado da autora em que investiga os conhecimentos históricos escolares pelo viés da cultura e da diferença, sob o enfoque das negociações acerca dos sentidos de brasilidade mobilizados por alunos das séries iniciais do Ensino Fundamental, utilizando como arcabouço teórico os estudos culturais pós-coloniais e o repertório analítico da crítica do discurso. Concluindo esse bloco, o texto de Daniel de Albuquerque Bahiense, "Articulações hegemônicas na construção discursiva sobre bons alunos de História" aborda a relação estudante/professor/conhecimento histórico, pensada na interface currículo, conhecimento e identidades sociais discursivas. $\mathrm{O}$ pesquisador procura entender como são fixados sentidos provisórios sobre "bons alunos de História" e o conhecimento histórico escolar.

O terceiro e último bloco, formado pelo encadeamento de seis textos, articula-se em torno da questão do conhecimento escolar e a escolha/produção do livro didático da disciplina. Em “Narrativas do 'outro’ no currículo de História: uma reflexão a partir de livros didáticos”, Adriana Soares Ralejo e Érika Elizabeth Vieira Frazão examinam como são abordados os conteúdos sobre História e cultura africana, afro-brasileira e indígena nas obras didáticas, após a promulgação das Leis 10.639/2003 e 11.645/2008. No texto seguinte “'Brasil: uma História dinâmica': desafios didáticos no Ensino de História”, partindo das articulações entre ensino de História e historiografia, os autores Ana Maria Monteiro, Adriana Soares Ralejo e Vicente Cicarino avaliam as mediações didático-culturais promovidas pelo livro didático Brasil: uma História dinâmica, publicado e utilizado na década de 1970. No terceiro texto, "A Revolta dos Malês nos livros didáticos de História e a Lei 10.639/2003: uma análise a partir da 'epistemologia social escolar"', os autores Luciene Maciel Stumbo Moraes e Wallace dos Santos Moraes estudam a presença dos conteúdos referentes ao movimento rebelde de 1835 em livros didáticos de História, tomando como aporte as contribuições teóricas da epistemologia social escolar, entendendo a inclusão desse conteúdo como desdobramento de um processo mais amplo de questionamento social a respeito da disputa de sentidos e memórias no âmbito da história ensinada consubstanciado pela implantação da Lei 10.639/2003. 
Os três últimos artigos abordam questões relacionadas à história do tempo presente. Cinthia Monteiro de Araujo, no texto "Por outras Histórias possíveis: construindo uma alternativa à tradição moderna”, compara duas obras didáticas com abordagens diferentes - a História Temática e a História Integrada - para perceber as tensões entre a tradição e as visões alternativas de articulação temporal dos processos históricos. Conclui alertando sobre os perigos de uma tradição curricular de História única e eurocêntrica, apoiada na perspectiva temporal linear e progressiva, ainda vigente em grande parte das escolas brasileiras. Com base em Hartog e Koselleck, destaca a necessidade de investimento em novas práticas pedagógicas abertas a uma concepção pluralista que envolve múltiplas narrativas, temporalidades e espacialidades. No quinto capítulo da Parte III, "Currículo de História e Projetos de Democratização: entre memórias e demandas de cada presente”, Carmen Teresa Gabriel e Érika Elizabeth Vieira Frazão analisam as transformações nos sentidos de conceitos como democracia e cidadania no decorrer das décadas posteriores à redemocratização, utilizando, para isso, três edições de um mesmo livro didático. Encerrando o bloco, o artigo "Demandas do tempo presente e sentidos de cidadania: redefinições e deslocamentos no currículo de História (anos 1980 x anos 2010)", cujos autores, Diego Bruno Velasco e Vitor Andrade Barcellos, analisam diferentes edições de uma mesma obra com o objetivo de identificar os deslocamentos no sentido de cidadania provocados pelas mudanças nas demandas sociais.

Pesquisa em Ensino de História apresenta, assim, um leque de perspectivas para quem se interesse pela área e suas faces de contato com a Historiografia, a Teoria e a Filosofia da História, os estudos sobre currículo, identidades e contemporaneidade. Os artigos amalgamados na obra acrescentam elementos para reflexão e abordagens paradigmáticas apoiadas nos repertórios crítico e pós-moderno, possibilitando o aprofundamento de perspectivas teórico-metodológicas e epistemológicas que articulam aspectos da teoria do currículo e da historiografia. Contribuem, também, para pensarmos a escola real e seu dia a dia, tanto pelos instrumentos didáticos quanto pelos seus sujeitos - docentes e discentes e seus saberes - desvelando-se, na visão dos autores, como um espaço repleto de contradições, mas, fundamentalmente, de possibilidades.

Como bem aponta Circe Bittencourt em seu prefácio, os temas e problemas apresentados pela obra "se abrem para formulações relevantes sobre as 
relações entre escola, cultura e poder" (p.19), o que para os autores traduz-se no comprometimento com a dimensão política desse campo, principalmente no tocante ao atendimento das demandas sócio-históricas do tempo presente, que constantemente mobilizam seus pesquisadores a questionar, reavaliar e reinventar o papel da História como componente curricular da educação básica.

Em tempos de ataques à História como disciplina escolar e de tentativas de criminalização da autonomia docente, o Ensino de História e a sua pesquisa transformam-se em arena fundamental na defesa dos valores democráticos e da diversidade, objetos privilegiados do campo a que nos dedicamos.

Resenha recebida em 28 de outubro de 2015. Aprovada em 12 de dezembro de 2015. 